\title{
Experimental Investigation of Switched Reluctance Motor Detailed Performance under Balanced and Unbalanced Operation

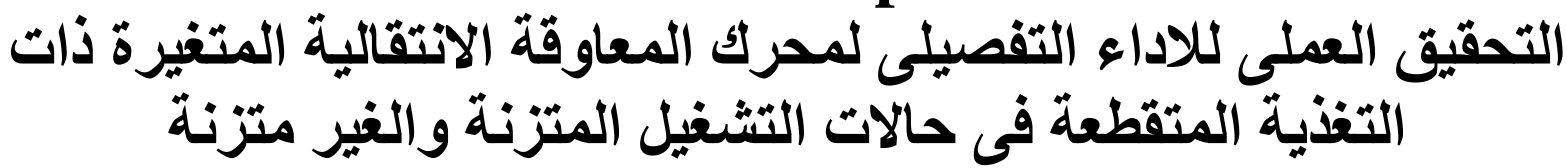

\author{
M. Hamouda, A. R. A. Amin and E. Gouda \\ Electrical Engineering Department, Mansoura University, Mansoura 35516, Egypt. \\ e-mail: $\underline{\text { m_hamouda26@mans.edu.eg }}$
}

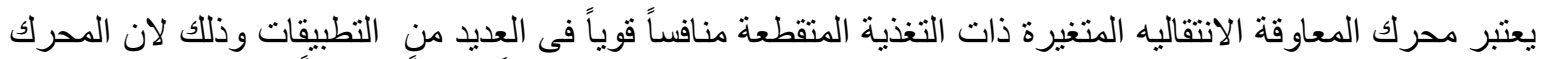

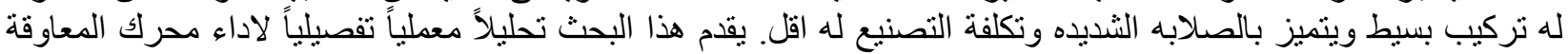

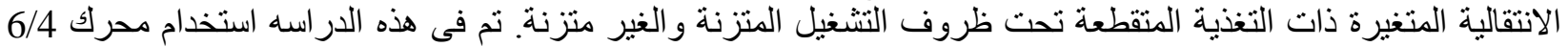

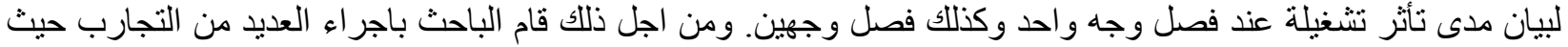

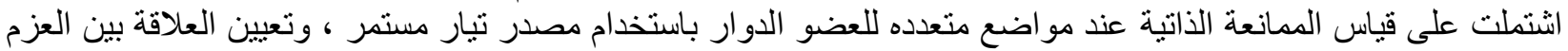

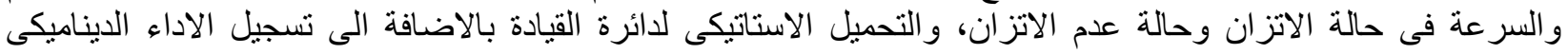

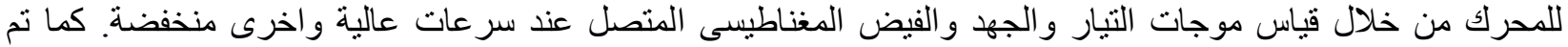
تسجيل شكل موجة التيار والجهد للمنبع لجميع حالات التشغيل. كما تناول البحث الحالة الدر اسية لتشغيل دائرة القياده للمحرك باستخدام مفتاح و احد لكل واجه (soft chopping ).

\begin{abstract}
The simple construction, robust design, and low cost of the Switched Reluctance Motor (SRM) made it an attractive candidate for many applications. This paper presents the detailed performance of 6/4 SRM. This motor has been considered in order to explain the effect of balanced and unbalanced operation. For this respect, extensive experimental tests and results have been obtained. The carried tests have been classified into Measuring the selfinductance using DC source at several rotor positions, Measuring the steady state balanced and unbalanced torquespeed characteristics, Static loading (R, RL Loads), and recoding the detailed SRM dynamic performance in terms of terminal quantities (current, voltage and flux linkage) at low speeds and high speeds. Moreover, this paper presents the operation of the driving circuit with one switch for each phase which is known as soft chopping operation. This case study is included to declare the SRM performance during this mode of operation.
\end{abstract}

\section{Index Terms}

Experimental, SRM, IGBT, bridge converter.

\section{Introduction}

SRM drives have great potential in motion control applications, because of their outstanding characteristics, which enable high performance in harsh environments such as high temperature and dusty environment [1][3]. Its simple construction due to absence of magnets, rotor conductors and brushes make it an attractive alternative to AC and DC motors for general-purpose industrial drives, as well as for high performance automotive drives and other applications. The rotor is basically a piece of steel (laminations) shaped to form salient poles making it well-suited for high speed operation [3]-[5]. The SRM promises a reliable and low-cost variable-speed drive and will undoubtedly take the place of many drives 
now using the cage induction and DC commutator machines in the short future [3].

SRM drive applications include Electric vehicles [6]-[7], Aerospace [8], Robotics [9], Variable speed and servo-type applications [2], [10], Renewable Energy System [11], Household appliances [1], [12]. Recentelly SRM has been used in many applications like :fuel pump, throttle control, oil pump, anti-lock bracking system (ABS), lawnmower, automatic doors in buildings and vehicles, and fans [13].

Torque and speed control applications of the SRM requires a rotor position information with reasonabl resolution and high degree of accuracy. Rotor position sensing unit is an integral part of the SRM drives control [14]. The drive circuit and the machine itself is considered as one integrated system, one part of such a system can't be separately designed without considering the other part.

This paper is organized as follows: Section II describes the SRM mathematical equations. Section III includes the SRM magnetic circuit structure and its driving circuit. Section IV describes the experimental tests, while the discussion of the experimental results is illustrated in section V. Section VI gives the conclusions drawn from this research. Section VII contains the appendix.

\section{Srm mathematical model II. 1. Mathematical Equations}

The SRM mathematical model is described by the following set of equations neglecting the mutual inductances.

$$
\begin{aligned}
& \mathrm{V}=\mathrm{R} \cdot i+\frac{\mathrm{d} \lambda(i, \theta)}{\mathrm{dt}} \\
& \lambda(i, \theta)=\mathrm{L}(i, \theta) \cdot \mathrm{i} \\
& \mathrm{V}=\mathrm{R} \cdot i+\mathrm{L}(i, \theta) \cdot \frac{\mathrm{d} i}{\mathrm{dt}}+i \frac{\mathrm{dL}}{\mathrm{dt}} \\
& \mathrm{V}=\mathrm{R} \cdot i+\mathrm{L}(i, \theta) \frac{\mathrm{d} i}{\mathrm{dt}}+i \frac{\mathrm{dL}(i, \theta)}{\mathrm{d} \theta} \cdot \frac{\mathrm{d} \theta}{\mathrm{dt}} \\
& \omega_{m}=\frac{\mathrm{d} \theta}{\mathrm{dt}} \\
& \mathrm{e}=\omega_{m} \cdot i \frac{\mathrm{dL}(i, \theta)}{\mathrm{d} \theta} \\
& \mathrm{V}=\mathrm{R} \cdot i+\mathrm{L}(i, \theta) \frac{\mathrm{d} i}{\mathrm{dt}}+\mathrm{e}
\end{aligned}
$$

The electrical power input to the motor is: V. $i=\mathrm{R} . i^{2}+\left[i . \mathrm{L}(i, \theta) \frac{\mathrm{d} i}{\mathrm{dt}}+\frac{1}{2} \omega_{m} i^{2} \frac{\mathrm{dL}(i, \theta)}{\mathrm{d} \theta}\right]+$

$\frac{1}{2} \omega_{m} \cdot i^{2} \frac{\mathrm{dL}(i, \theta)}{\mathrm{d} \theta}$

V. $i=\mathrm{R} . i^{2}+\frac{\mathrm{d}}{\mathrm{dt}}\left[\frac{1}{2} \mathrm{~L}(i, \theta) \cdot i^{2}\right]+T \cdot \omega_{m}$

$\mathrm{W}_{f}=\frac{1}{2}\left[\mathrm{~L}(i, \theta) \cdot i^{2}\right]$

$\mathrm{T}=\frac{1}{2} i^{2} \frac{\mathrm{dL}(i, \theta)}{\mathrm{d} \theta}$

where the symbols $V, i, R, \lambda, \omega_{m}, e, L, T, \theta$ and $\mathrm{W}_{\mathrm{f}}$ are the voltage, current, resistance, flux linkage, speed, induced voltage, selfinductance, phase torque, rotor angle, stored magnetic field energy respectively [1]-[3].

\section{2. SRM Equivalent Circuit}

From equation (7), the equivalent circuit of the SRM can be considered as shown in Fig.1. The switching frequency $\left(f_{s w}\right)$ for the switch SW can be calculated as a function of motor mechanical speed $\mathrm{n}(\mathrm{rpm})$ by equation (12).

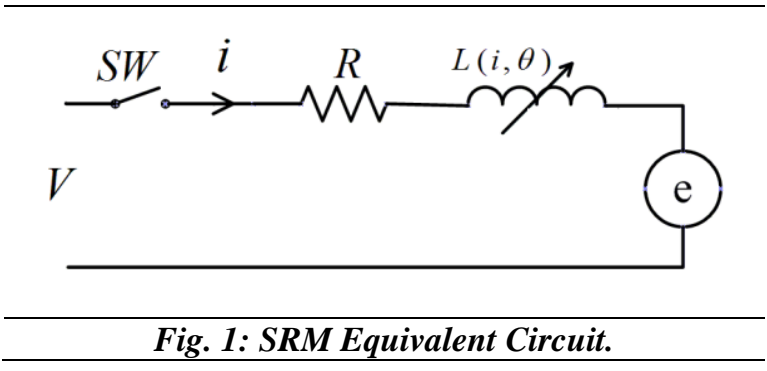

$f_{s w}=N_{r} \frac{n}{60}$

where $\mathrm{N}_{\mathrm{r}}$ is the number of rotor poles.

\section{Experimental SRM}

\section{Prototype}

\section{1. SRM Magnetic Circuit Configuration}

The basic dimensions of the 6/4 SRM is given in the appendix. The SRM magnetic circuit structure and main geometry configurations are shown in Fig. 2.

Figure. 2 shows 6 stator poles; each pole is wounded with a concentrated winding. The six windings compose three independent phases. Each phase can be either connected in 
series or parallel of two opposite poles windings. Moreover, this magnetic circuit is equipped with nine search coils. Three search coils are wounded on the stator yoke and known as Y1-1', Y2-2', and Y3-3'; while the remaining search coils are wound to measure the stator pole flux linkage (termed as P1-1', P2-2', P2-2', P4-4', P5-5', and P6-6').

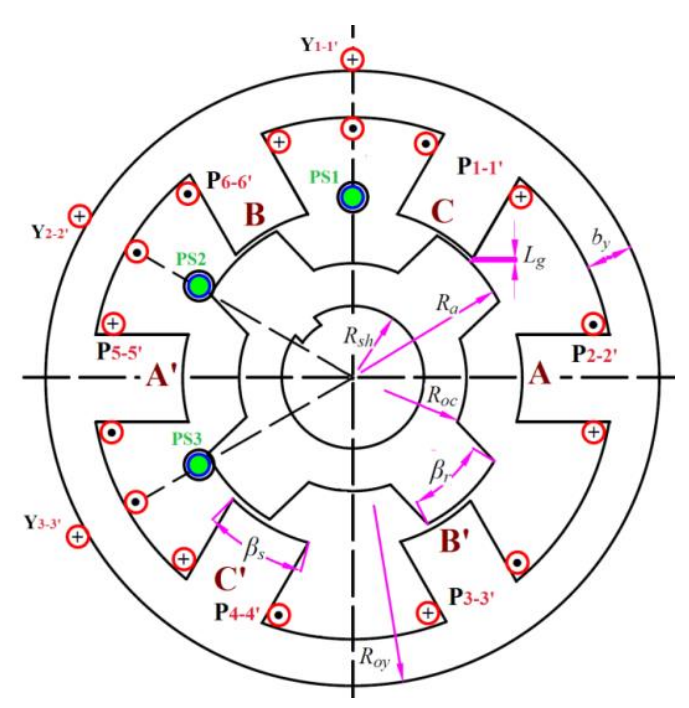

Fig. 2:SRM Magnetic Circuit Configuration.

Also, Fig.2 shows the position sensors which are termed PS1, PS2 and PS3. Moreover, this figure illustrates the unaligned position of phase $\mathrm{A}\left(\theta=0 \mathrm{mech}^{\circ}\right)$. At this position sensor PS3 outputs high indicating the right position for phase A excitation to rotate the motor in anticlockwise direction. After 30 $\mathrm{mech}^{\circ}$, sensor PS1 outputs high indicating the right position for phase $\mathrm{B}$ excitation. After another $30 \mathrm{mech}^{\circ}$, sensor PS2 outputs high indicating the right position for phase $\mathrm{C}$ excitation. This procedure is repeated every $90^{\circ}$ of rotor position [15]. The phase conduction sequence can be as following:

Phase A $0^{\circ} \leq \theta \leq 30^{\circ}$,

Phase B $30^{\circ} \leq \theta \leq 60^{\circ}$,

Phase C $60^{\circ} \leq \theta \leq 90^{\circ}$.

\section{2. SRM driving system}

Fiqure. 3 illustrates the complete block diagram for the SRM drive system. This figure shows that the driving circuit consists of speed controller, hysteresis current controller, IGBT converter circuit, filters and encoder.

The input of the speed controller is the error of the speed signal which they are the difference of the reference speed and the actual signal measured by the tachogenerator. However, the hysteresis current controller regulates the motor current according to the commanded value especially at low speed operation. On the other hand, the IGBT converter circuit is explained below.

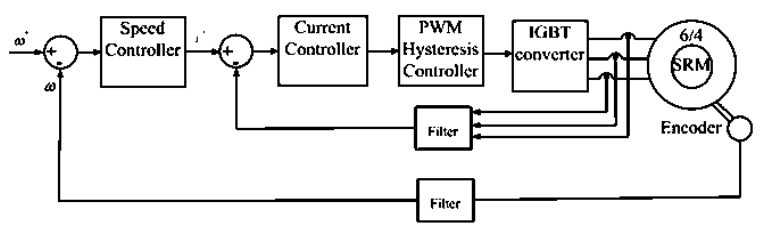

Fig. 3: a complete block diagram of SRM drives system (Closed-loop speed-control).

\section{The IGBT Converter}

The most flexible and the most versatile four-quadrant SRM converter is the classic bridge converter, which requires two switches and two diodes per phase. The major advantage of this converter is its flexibility in current control. Each phase can be controlled in unindependent way which is very essential for very high speed operation. The motor phases are similarly connected. The asymmetric bridge converter for one phase is shown in Fig.4. The rating of each component is chosen to work safely.

The bridge converter operates in three modes. When both switches $\mathrm{Q}_{1}$ and $\mathrm{Q}_{2}$ are closed, current flows from the source through the phase winding. When $\mathrm{Q}_{1}$ is open and $\mathrm{Q}_{2}$ is closed (soft chopping), the phase current freewheels through the phase winding, $\mathrm{D}_{2}$ and $\mathrm{Q}_{2}$. When both switches $\mathrm{Q}_{1}$ and $\mathrm{Q}_{2}$ are open (hard chopping), the current flows through the feedback diodes $\mathrm{D}_{1}$ and $\mathrm{D}_{2}$ against the supply voltage. The energy stored in the phase 
winding inductance is returned to the $\mathrm{dc}$ source and the current quickly decays to zero.

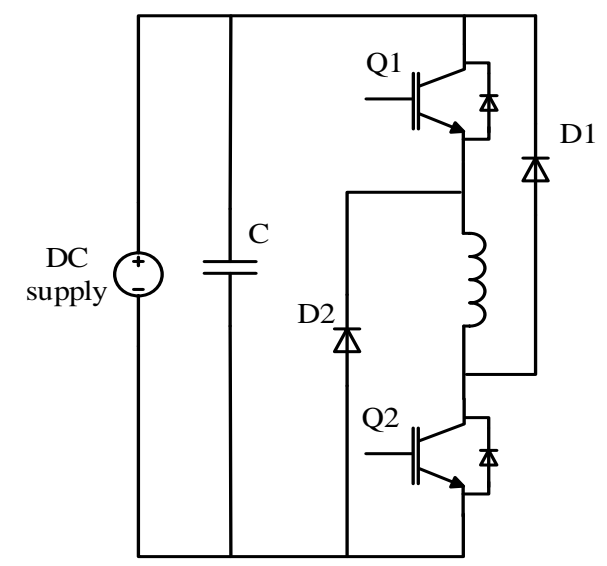

Fig.4: asymmetric converters for SRM with free-wheeling and regeneration capability.

\section{Experimental Tests And Results}

Several tests have been carried out on the SRM prototype to illustrate the detailed motor performance. The detailed performance has been investigated by carrying out the following tests.

1.Measuring the self-inductance using DC source;

2.Measuring the steady state balanced and unbalanced torque-speed characteristics;

3.Static loading (R, RL Loads); and

4. Recoding the detailed SRM dynamic performance.

Figure. 5 shows the tests that have been listed before. The following sections explain the testes carried out with their results.

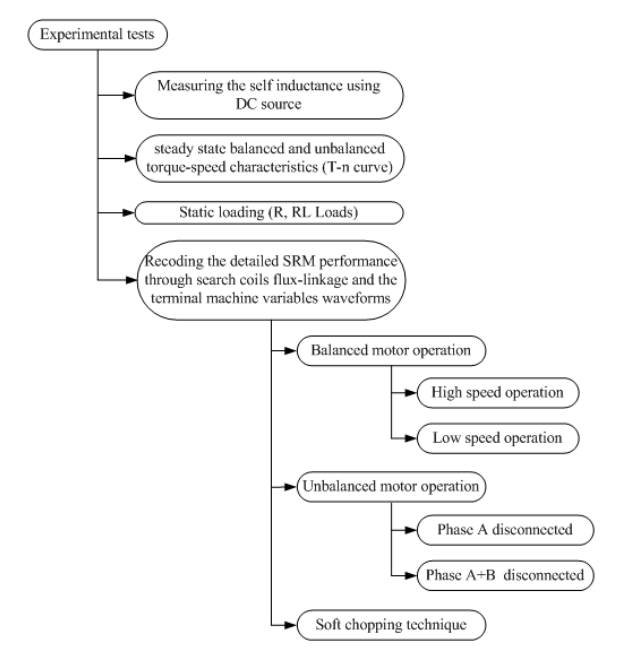

Fig.5: the experimental tests flowchart.

\section{Measuring The Self-Inductance Using DC Source}

The inductance can be measured with a pulsed DC voltage applied on the phase winding where the rotor is blocked in a certain position. Figure.6 shows the voltage and current waveforms registered with tested phase when the rotor is blocked at $\theta=45^{\circ}$ (the aligned position). According to the equivalent circuit shown in Fig. 1 with $e=0$, the term $\frac{d \lambda(i, \theta)}{d t}$ can be calculated after the subtraction of the resistive voltage drop. The integration of this term gives the phase self-inductance according to equation (13). Repeating this procedure at different rotor positions several times can produce the inductance profile as illustrated in Fig.7.

The inductance profile is plotted as a function of rotor position at various current values. Therefore, Fig.7 shows that the saturation levels are changed according to the current values.

$L(i, \theta)=\frac{\lambda(i, \theta)}{d i}$ 

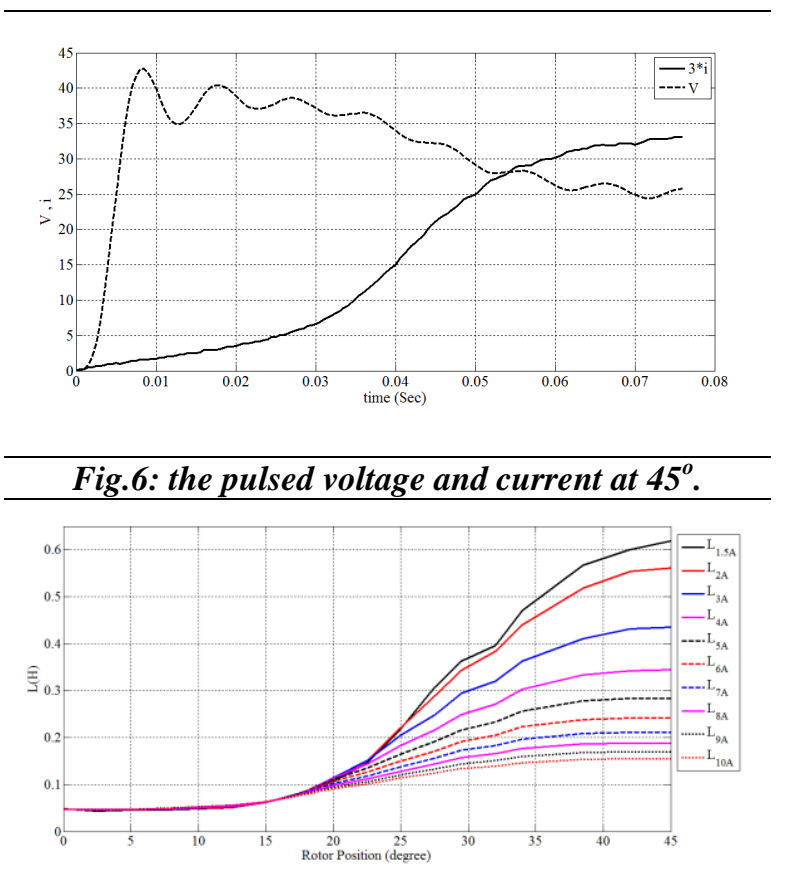

Fig.7: the measured per phase inductance.

\section{Measuring The Steady State Balanced And Unbalanced Torque-Speed Characteristics}

Figure.8 illustrates the measured torquespeed characteristics under balanced motor operation. The balanced operation curve has been divided into two sections which are considered as current controlled mode (at low speeds) and angle controlled mode (at high speeds). The torque in the low speed zone $\left(T_{L . S}\right)$ as a function of motor speed is fitted as illustrated by equation (14); while the torque in the high speed zone can be fitted as shown by equation (15).

$$
\begin{aligned}
& \mathrm{T}_{\mathrm{L} . \mathrm{s}}=5.1140 * 10^{-7} * \mathrm{n}^{2}-0.0023 * \mathrm{n}+ \\
& 3.3339 \\
& \mathrm{~T}_{\mathrm{H} . \mathrm{s}}=1.1098 * 10^{-7} * \mathrm{n}^{2}-0.0012 * \mathrm{n}+ \\
& 3.1372
\end{aligned}
$$

From these equations, the SRM behaviour can be classified as series characteristics where the speed is decreased rapidly with the increased load torque. From equation (14), the starting torque has been found to be $3.3339(\mathrm{Nm})$. On the other hand, at no-load, the speed has been calculated to be
$5500 \mathrm{rpm}$. This value has been measured before the dynamic breaking is installed.

Figure.9 shows the two unbalanced torque-speed characteristics for phase A disconnected as well as phases $\mathrm{A}$ and $\mathrm{B}$ disconnected. The fitted motor torque for the unbalanced motor operation with phase A disconnected is illustrated by equation (16). The motor torque with two phases disconnected is fitted as seen by equation (17).

$\mathrm{T}_{\mathrm{A}_{-} \text {off }}=2.05 * 10^{-7} * \mathrm{n}^{2}-0.0012 * \mathrm{n}+$ 2.106

$\mathrm{T}_{\mathrm{A}, \mathrm{B}_{-} \text {off }}=2.103 * 10^{-7} * \mathrm{n}^{2}-8.694 *$

$10^{-\overline{4}} * \mathrm{n}+1.1117$

The single phase operation for the SRM declares that a new phenomenon for such machine has occurred. The authors may consider the running operation with one single phase connected to the supply is due to the rotor saliency.
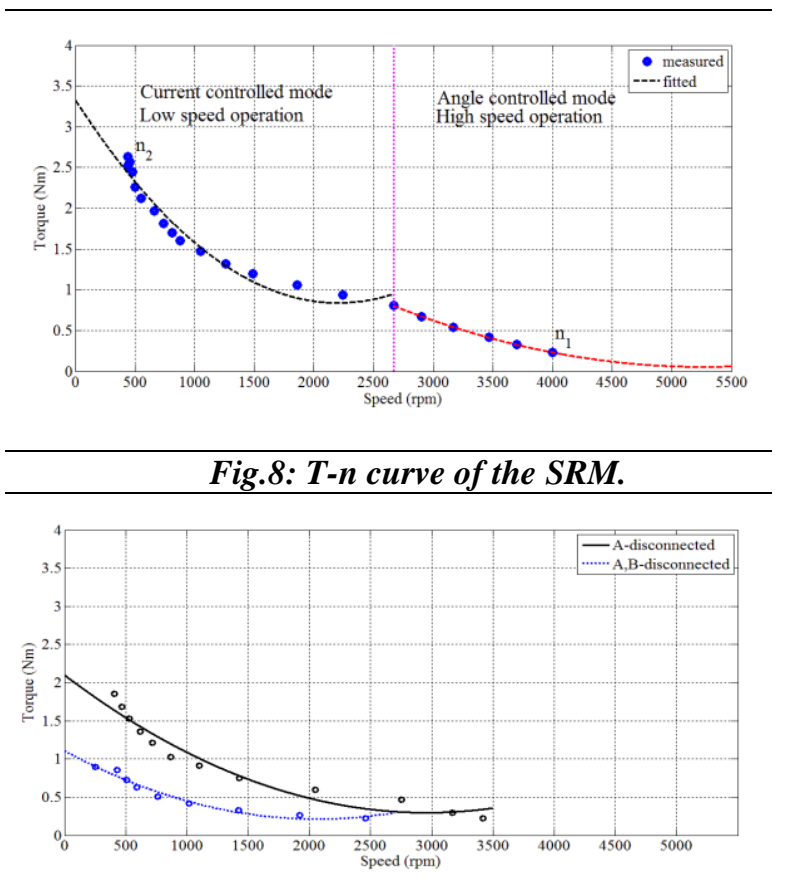

Fig.9: Unbalanced Torque-Speed Curve of the SRM.

\section{Static Loading Operation}

With step by step building of the drive system, the static loading is considered to 
check the drive system isolatelly away from the motor. These types of tests have been carried out to monitor the three phases circuits. Fig.10 to Fig.12 show the experimental results that are obtained with static loading. In case of static R-Load, the supply current and supply voltage waveforms are shown in Fig.10. The supply voltage in R-load is nearly a pure DC waveform. The three phases' currents are illustrated in Fig.11. The current is in phase with the voltage. At the instant of switchingoff, the current decays instantaneously to zero. On the other hand, the experimental results for static RL-loading are shown in Fig.12. The current lags the voltage by certain angle depending on the inductance value. At the instant of switching-off, the stored magnetic field energy in the winding will keep the current in the same direction until it is depleted. The voltage becomes negative until the phase current reaches zero. Fig.12(b) illustrates a transient overshoot on the phase voltage due to the switching on and off operation. This effect can be eliminated by allowing the supply voltage to accept the stored magnetic field energy $\left(\frac{1}{2} \mathrm{~L} \cdot i^{2}\right)$. This elimination can be achieved by connection of capacitor bank in parallel with the terminal supply voltage.

By comparing the current passing through R-load and RL-load, spikes on RLload current could be eliminated by using filters.

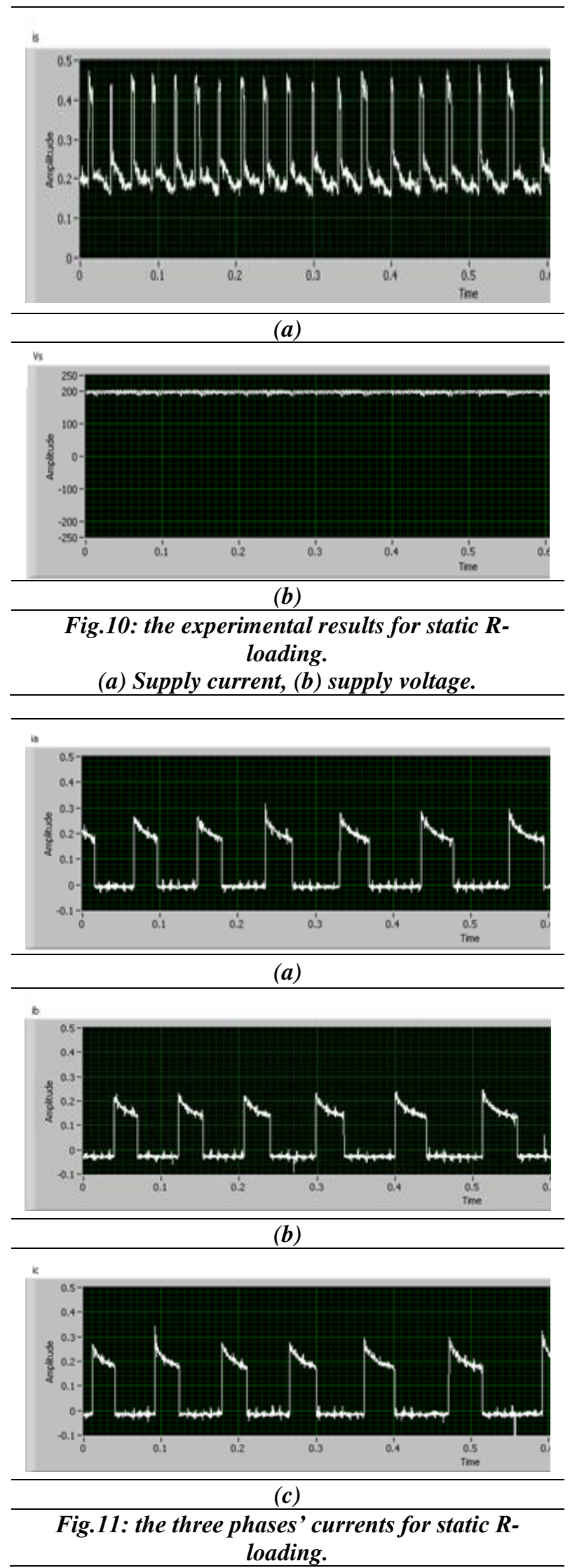




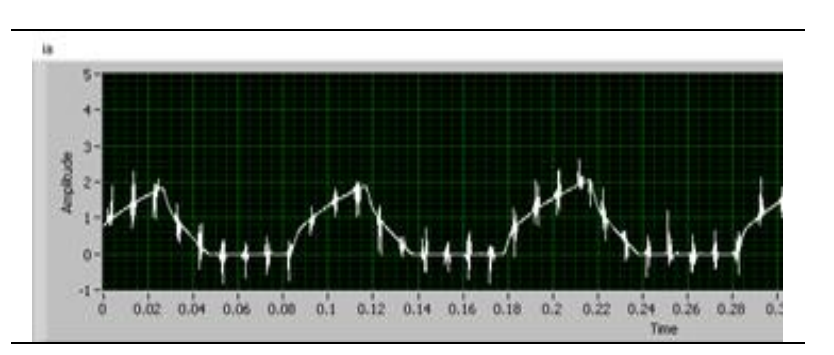

(a)

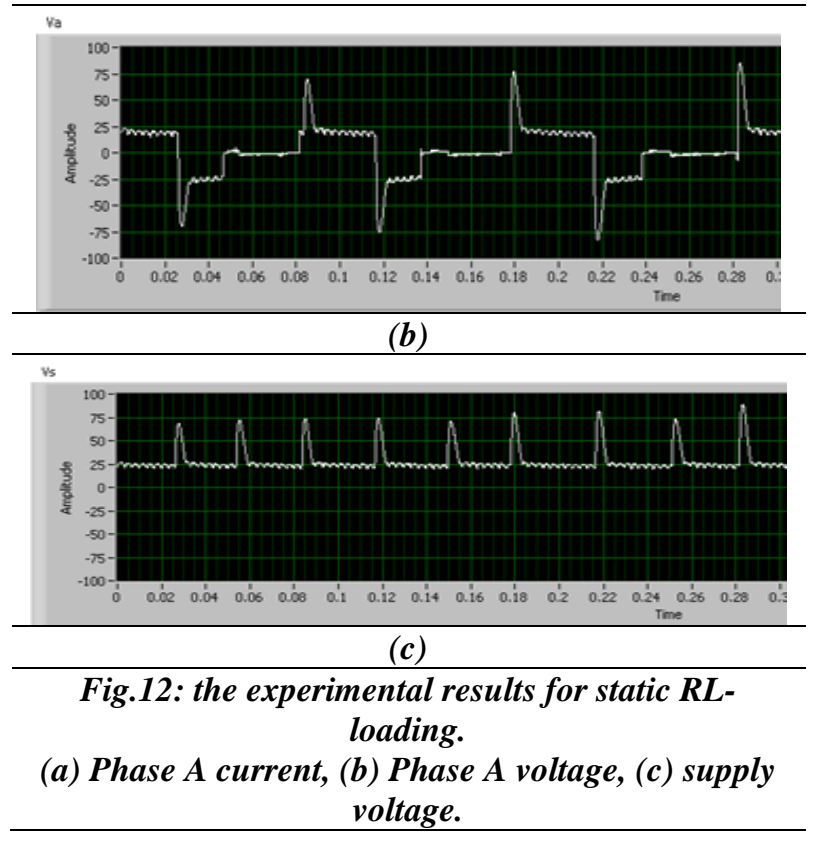

\section{The Detailed SRM Dynamic} Performance

This section includes the motor operation under balanced, unbalanced operations as well as the soft chopping technique.

\section{A. Balanced motor operation}

The detailed performance of the SRM is investigated in terms of recording the phases current, the supply current, the supply voltage, the phases voltage, the pole flux-linkage as well as the yoke flux-linkage waveforms. These waveforms are given for two speeds (high speed $\mathrm{n}_{1}=4050$ and low speed $\mathrm{n}_{2}=440$ rpm) as shown in T-n curve. Fig.8 shows the balanced speeds $n_{1}$ and $n_{2}$.

At high speed of $4050 \mathrm{rpm}$, the backemf (e) in the motor phase windings is considered. It works against the supply voltage to reduce the current. The supply voltage and current waveforms are shown in Fig.13. The supply voltage has large oscillations. A capacitor bank has been connected in parallel with the source to reduce the voltage fluctuations. The applied voltage on each phase seems to be a single pulse as shown in Fig. 14 (a). The peak value of phase current is about 2(A) as shown in Fig.14 (b). The fluxlinkgae waveform is well shaped as triangle as shown in Fig.14(c).

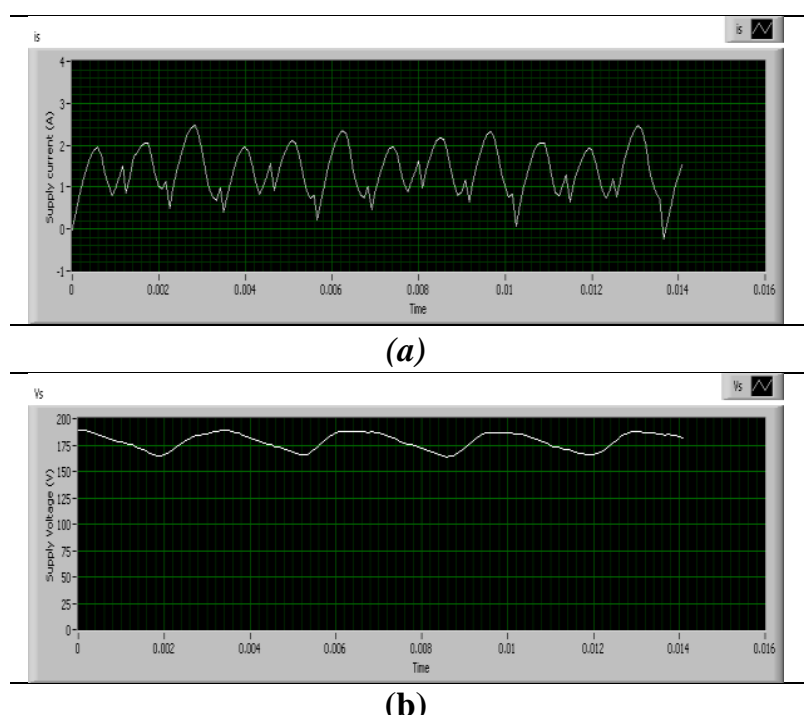

Fig.13: the experimental results for balanced motor operation at high speed of $n_{1}=4050 \mathrm{rpm}$. (a) Supply current, (b) Supply voltage. 


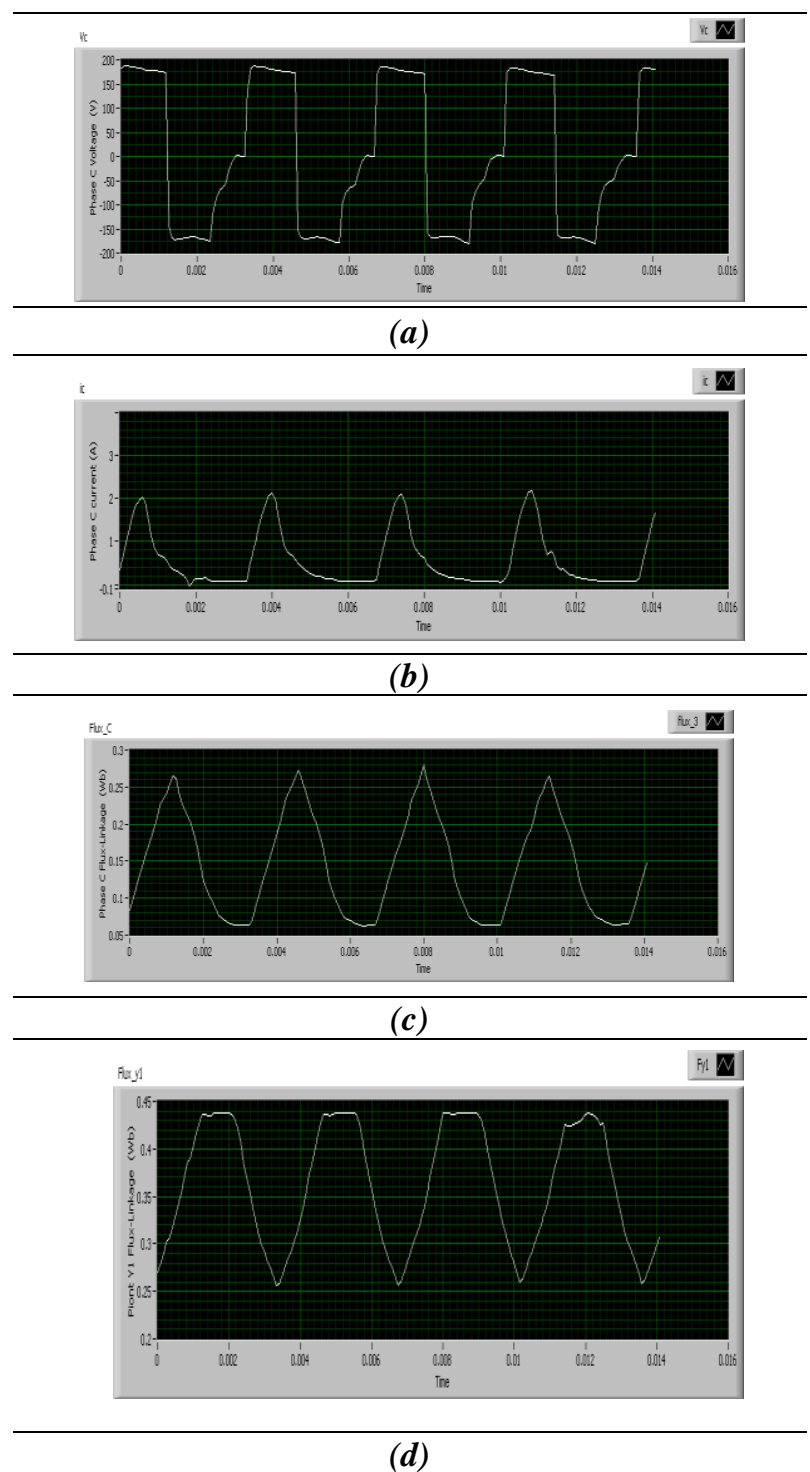

Fig.14: the experimental results for balanced motor operation at high speed of n1=4050 rpm. (a) Phase C voltage, (b) Phase C current, (c) Phase C flux, (d) yoke flux.

At low speeds, the back-emf (e) is considered small compared to the supply voltage. Accordingly the drawn current will rise very rapidly to a serious value. The hysteresis current controller is employed to regulate the current to an accepted value. The maximum permissible current is limited to 3.5(A) as shown in Fig.15 (a). The voltage is varying between positive and negative value as shown in Fig.15 (b) (hard chopping). The phase flux linkage is no more a triangle shape compared to the case of high speed as observed by Fig.15(c). The flux linkage in the stator yoke can be seen in Fig.15 (d).
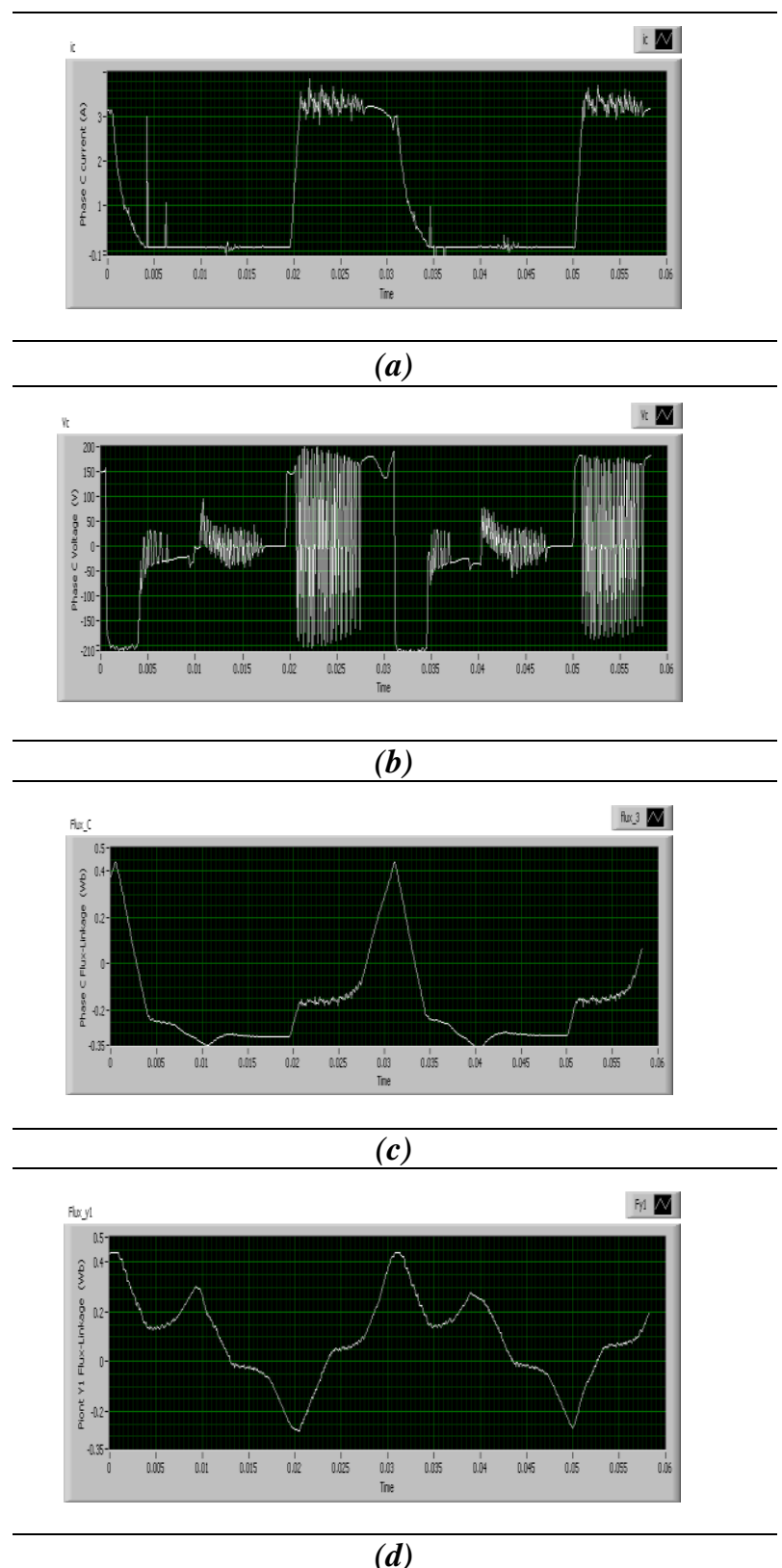

Fig.15: the experimental results for balanced motor operation Low speed of $n 2=440 \mathrm{rpm}$. (a) Phase $C$ voltage, (b) Phase C current, (c) Phase C flux, (d) yoke flux.

The supply current crosses the zero line; this means that the current is flowing back to the dc supply. The supply voltage fluctuations are greater compared to the case of high speed operation as shown in Fig.16. 

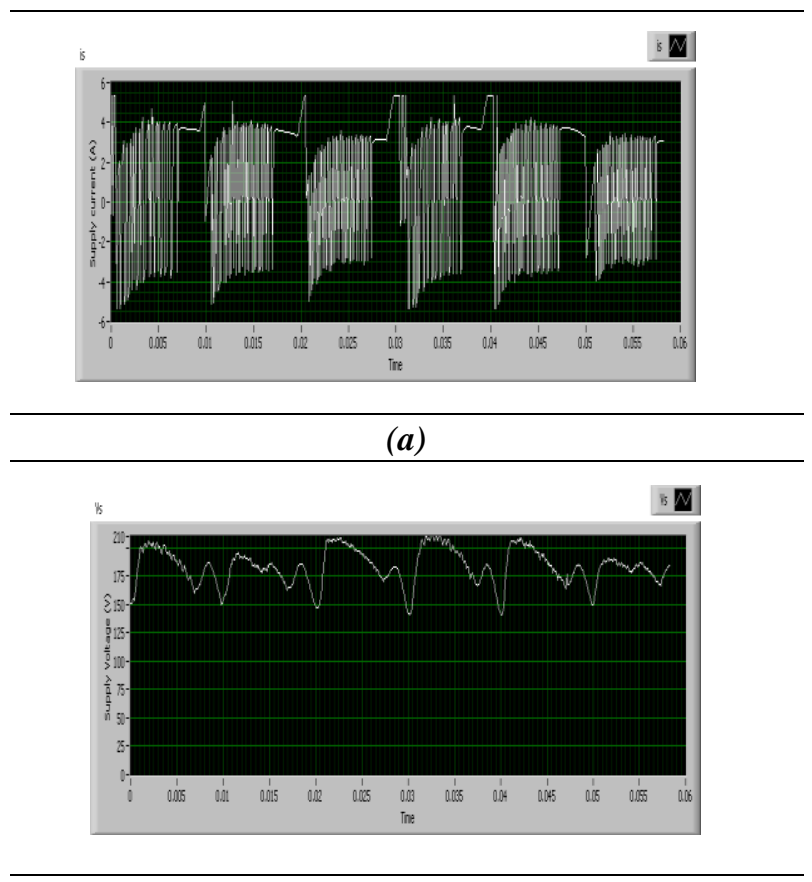

\begin{tabular}{c}
\hline (b) \\
\hline Fig.16: the experimental results for balanced motor \\
operation Low speed of $n_{2}=440$ rpm. (a) Supply \\
current, (b) Supply voltage
\end{tabular}

\section{B. Unbalanced motor operation}

Figure. 17 and 18 show the experimental results of the motor under unbalanced operation. The motor can operate with one phase disconnected as shown in Fig.17 and even with two phases disconnected as seen by Fig.18.

After the disconnection of phase A, the motor speed decreases from $3720 \mathrm{rpm}$ at noload to $3220 \mathrm{rpm}$. The motor draws more current to regain its speed as shown in Fig.17 $(b, c)$.

On the other side, with one phase excited (just only phase $\mathrm{C}$ is energized). The motor speed settles at $2290 \mathrm{rpm}$. The motor current is increased to one and half its original value as shown in Fig.18(c).

It is concluded that the maximum current drawn by the motor during balanced operation, one phase disconnected, and two phases disconnected were 2(A), 2.3(A), and 3 (A) respectively. These current values have been recorded at speeds $3720 \mathrm{rpm}, 3220 \mathrm{rpm}$, and $2290 \mathrm{rpm}$ respectively. On the other hand, the corresponding pole flux linkages have been affected according to the currents. The flux linkage waveforms are also affected.

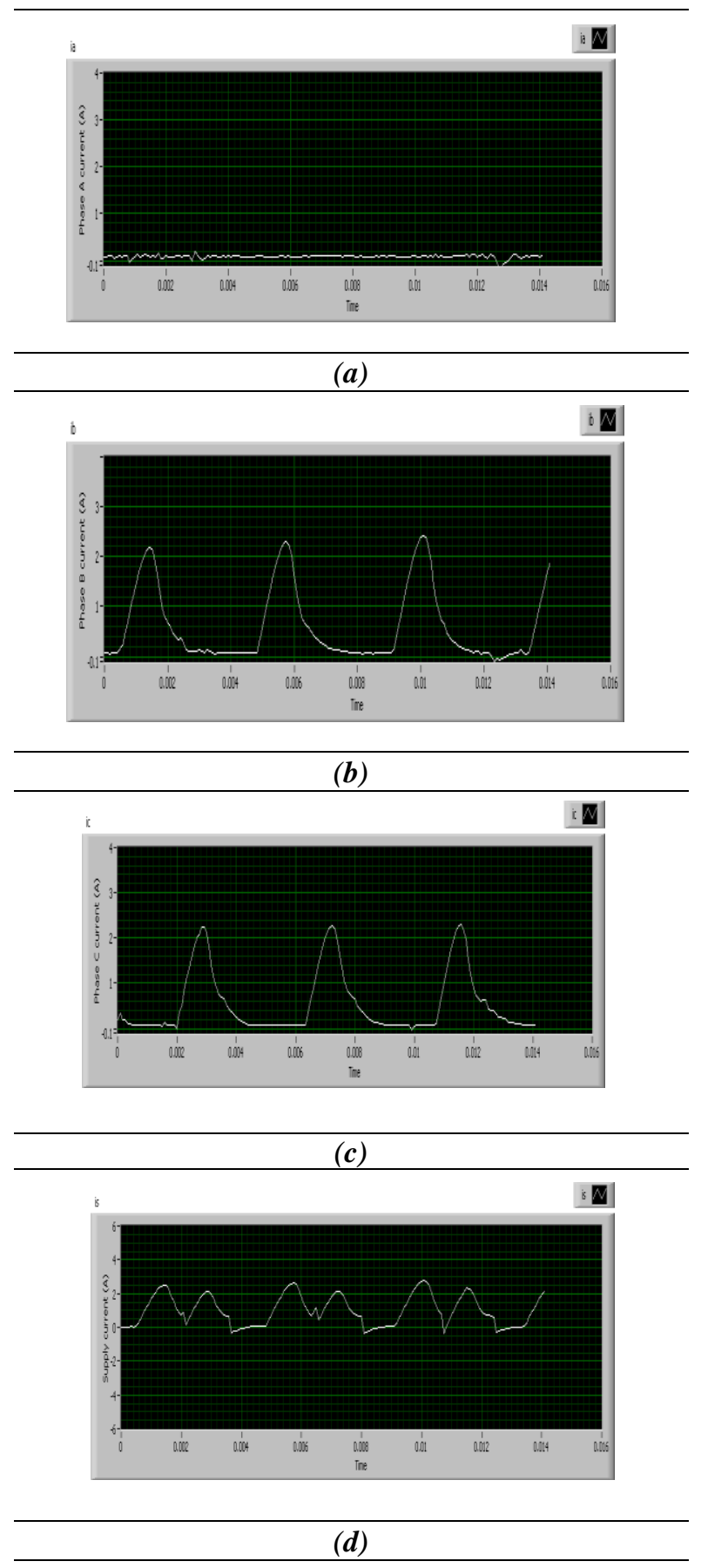

Fig.17: the experimental results for unbalanced motor operation with phase A disconnected (B) phase A and B disconnected. (a) Phase A current, (b) Phase B current, (c) Phase C current, (d) Supply current. 

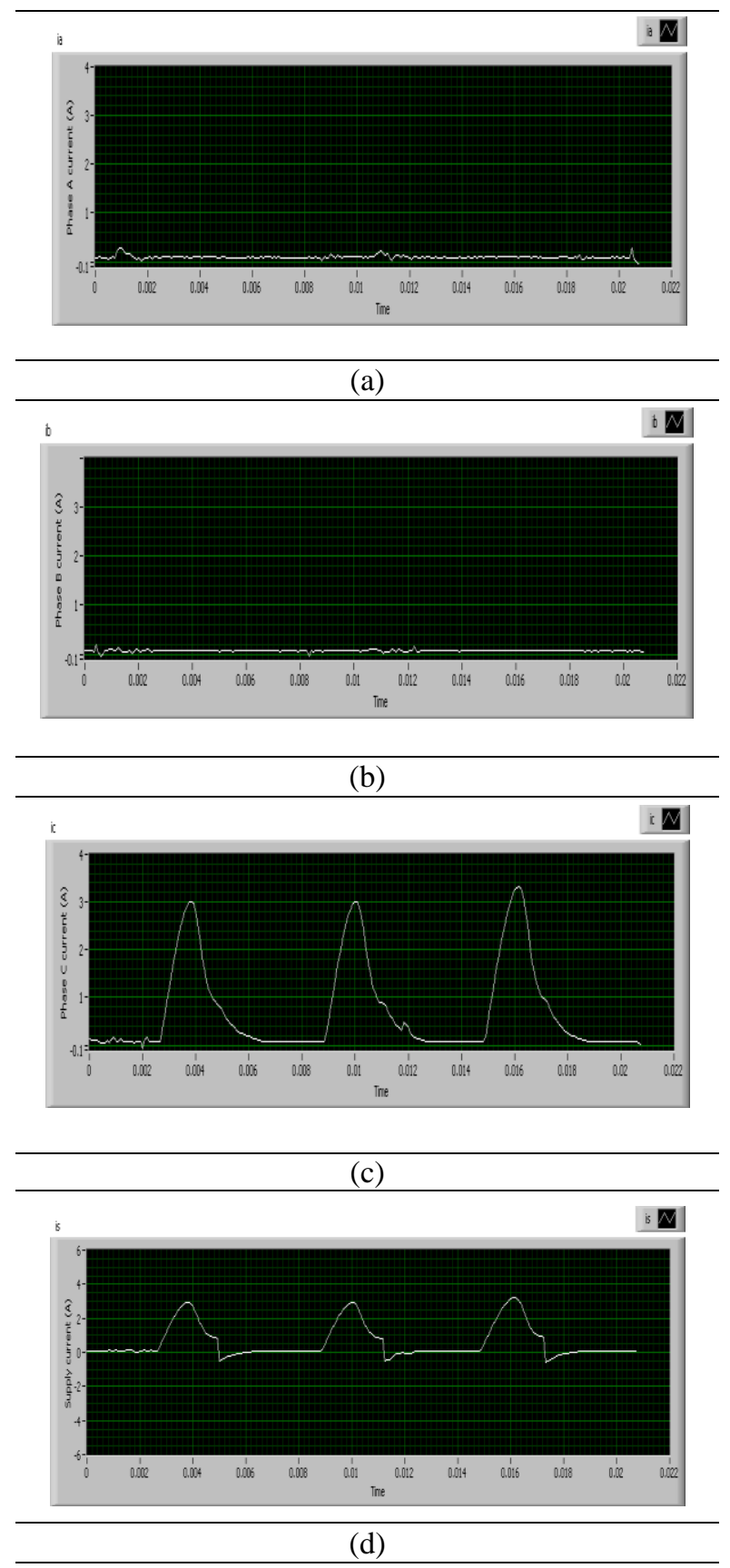

Fig.18: the experimental results for unbalanced motor operation with phase A and B disconnected.

(a) Phase A current, (b) Phase B current, (c) Phase C current, (d) Supply current.

\section{Soft chopping process}

Figure.19 shows some of the experimental results for hard and soft chopping process. The current is limited to a maximum value of 3.5(A) as shown in Fig.19 (a). Soft chopping technique reduces the switching losses in power switching devices (IGBTs). The motor voltage changes between positive and zero (soft chopping) as seen in Fig.19 (b). The phase-flux linkage is nearly a triangle as illustrated in Fig.19(c). The yokeflus linkage is shown in Fig.19 (d).

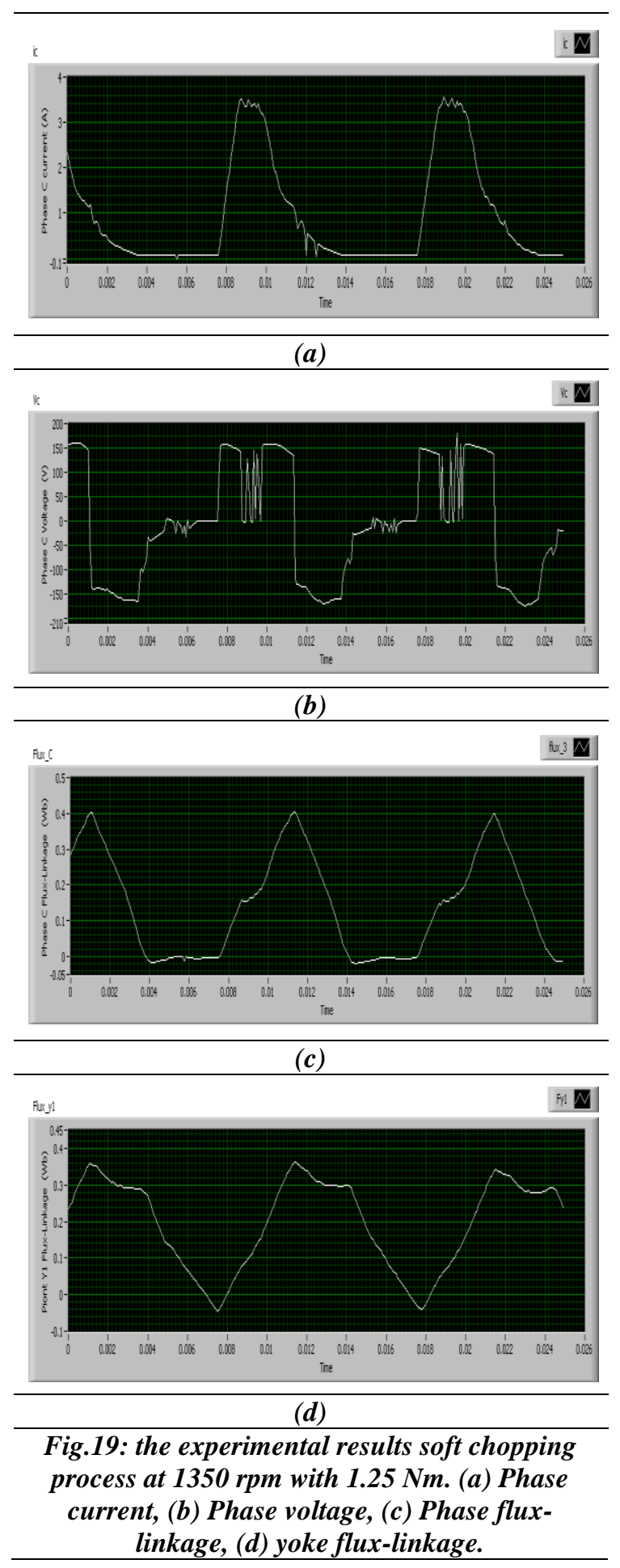




\section{Conclusion}

The detailed performance of the SRM has been investigated in terms of several tests. These tests have been carried out under balanced and unbalanced operation. From these tests, measuring the phase selfinductance using DC source at different levels of current illustrates the saturation effect, the static loading has been illustrated in order to show the balance between the phases, The overshoot on the supply voltage waveform shows the importance of eliminating this phenomenon by connecting parallel capacitors with the supply terminals, The torque-speed curve for balanced and unbalanced operation has been recorded, the detailed performance of the switched reluctance motor in terms of recording the phases current, supply current, supply voltage, phases voltages, pole flux linkage and yoke flux linkage waveforms have been recorded and discussed at high speeds and low speeds. Moreover, the soft chopping process has been carried out to illustrate the effect of eliminating one switch operation in the driving circuit. A new phenomenon has been declared when the SRM operates less than one phase excitation which may be related to the motor saliency.

\section{References}

[1.] R. Krishnan, "Switched Reluctance Motor Drives: Modeling, Simulation, Analysis, Design, and Applications", Boca Raton, FL: CRC Press, pp.398, 2001.

[2.] T. J. E. Miller, "Electronic Control of Switched Reluctance Machines", Oxford: Newness, pp. 272, 2001.

[3.] I. Husain, "Minimization of torque ripple in SRM drives", IEEE Trans. on Industrial Electronics, Vol. 49, No. 1, pp. 28-39, February 2002.

[4.] J. Ye, B. Bilgin and A. Emadi,"An Extended-Speed Low-Ripple Torque Control of Switched Reluctance Motor
Drives", IEEE Trans. on Power Electronics, Vol. 30, No. 3, pp. 1457 1470, 2015.

[5.] H. Hannoun, M. Hilairet, and C. Marchand, "Design of an SRM Speed Control Strategy for a Wide Range of Operating Speeds" IEEE TRANS. ON Industrial Electronics, Vol. 57, No. 9, pp. 2911 - 2921, September 2010.

[6.] F. L. M. dos Santos, J.Anthonis, F. Naclerio, J. J. C. Gyselinck, H. V. d. Auweraer, and L. C. S. Góes, "Multiphysics NVH Modeling: Simulation of a Switched Reluctance Motor for an Electric Vehicle", IEEE TRANS. ON Industrial Electronics, Vol. 61, No. 1, pp. 469 - 476, January 2014.

[7.] M. Takeno, A.Chiba, N. Hoshi, S.Ogasawara, M.Takemoto, M. A. Rahman, "Test Results and Torque Improvement of the $50-\mathrm{kW}$ Switched Reluctance Motor Designed for Hybrid Electric Vehicles" IEEE Trans. On Industry Applications, Vol. 48, No. 4, pp. 1327-1334, August 2012.

[8.] M. Villani, M. Tursini, G. Fabri and L. Di Leonardo, "A switched-reluctance motor for aerospace application", International Conference on Electrical Machines (ICEM), pp. 2073 - 2079, Septemper 2014.

[9.] S. Song, W. Liu and Y. Wang, "Modeling, dynamic simulation and control of a four-phase switched reluctance motor", IEEE International Conference on Control and Automation, ICCA, pp. 1290-1295, May 302007.

[10.] T. J. E. Miller, "Optimal design of switched reluctance motors," IEEE Trans. Ind. Electron., Vol. 49, No. 1, pp. 15-27, 2002.

[11.] R. Jayapragash, C. Chellamuthu, "Analysis of Switched Reluctance Machine Using FEA for Renewable Energy System", International Conference on Power, IEEE, Energy and Control (ICPEC), pp.777-781, 2013. 
E: 40 M. Hamouda, A. R. A. Amin and E. Gouda

[12.] H. Chen, and J. J. GU, "Switched Reluctance Motor Drive With External Rotor for Fan in Air Conditioner" IEEE/ASME TRANS. ON MECHATRONICS, Vol. 18, No. 5, pp. 1448 - 1458, October 2013.

[13.] www.microchip.com

[14.] I. Husain, A.O. Khalil, "Modeling and analysis of four quadrant sensorless control of a switched reluctance machine over the entire speed range", University of Akron, pp. 154, August, 2005. (PhD)

[15.] [15] Y. H. Yoon, K. H. Jeong, J.M. Kim, C. Y. Won, and J. W. Kim, "A Low Cost Position Sensing Method with Optical Sensors for Switched Reluctance Motor", Journal of Power Electronics, Vol. 5, No. 3, pp.240-246, July 2005

\section{Appendix}

Table $i$

The machine dimensions in [mm].

\begin{tabular}{|c|c|c|}
\hline Geometry parameter & symbol & Value \\
\hline Rated voltage & $V$ & 270 \\
\hline Shaft radius & $R_{s h}$ & 19.05 \\
\hline Rotor core outer radius & $R_{o c}$ & 30.5 \\
\hline Rotor outside radius & $R_{a}$ & 44.2 \\
\hline Stator outside radius & $R_{\text {oy }}$ & 82.5 \\
\hline Stator yoke width & $b_{y}$ & 12.5 \\
\hline Air gap length & $L_{g}$ & 0.25 \\
\hline Rotor pole arc angle $\left[^{\circ}\right]$ & $\beta_{r}$ & 33 \\
\hline stator pole arc angle $\left[{ }^{\circ}\right]$ & $\beta_{s}$ & 30 \\
\hline Core length & $L_{a}$ & 103 \\
\hline Turns per phase & $N$ & 400 \\
\hline Phase resistance & $R$ & 2.267 \\
\hline
\end{tabular}

